\title{
Use of geomorphic, hydrologic, and nitrogen mass balance data to model ecosystem nitrate retention in tidal freshwater wetlands
}

\author{
E. D. Seldomridge and K. L. Prestegaard \\ Department of Geology, University of Maryland, College Park, MD 20742, USA \\ Correspondence to: E. Seldomridge (emily.seldomridge@gmail.com) \\ Received: 19 December 2011 - Published in Biogeosciences Discuss.: 1 February 2012 \\ Revised: 7 June 2012 - Accepted: 13 June 2012 - Published: 19 July 2012
}

\begin{abstract}
Geomorphic characteristics have been used as scaling parameters to predict water and other fluxes in many systems. In this study, we combined geomorphic analysis with in-situ mass balance studies of nitrate retention (NR) to evaluate which geomorphic scaling parameters best predicted NR in a tidal freshwater wetland ecosystem. Geomorphic characteristics were measured for 267 individual marshes that constitute the freshwater tidal wetland ecosystem of the Patuxent River, Maryland. Nitrate retention was determined from mass balance measurements conducted at the inlets of marshes of varying size $(671,5705$, and $536873 \mathrm{~m}^{2}$ ) over a period of several years. Mass balance measurements indicate that NR is proportional to total water flux over the tidal cycle. Relationships between estimated tidal prism (calculated water volume) for spring tides and various geomorphic parameters (marsh area, total channel length, and inlet width) were defined using measurements from air photos and compared to field data. From these data, NR equations were determined for each geomorphic parameter, and used to estimate NR for all marshes in the ecosystem for a reference spring (high) tide. The resulting ecosystem NR estimates were evaluated for (a) accuracy and completeness of geomorphic data, (b) relationship between the geomorphic parameters and hydrologic flux, and (c) the ability to adapt the geomorphic parameter to varying tidal conditions. This analysis indicated that inlet width data were the most complete and provided the best estimate of ecosystem nitrate retention. Predictions based on marsh area were significantly lower than the inlet width-based predictions. $\mathrm{Cu}$ mulative probability distributions of nitrate retention indicate that the largest $3-4 \%$ of the marshes retained half of the total nitrate for the ecosystem.
\end{abstract}

\section{Introduction}

Ecosystem functions, such as nitrate retention, are difficult to predict for entire ecosystems due to the complex interactions of linked biogeochemical and physical controls on ecosystem processes (Boyer et al., 2006; Seitzinger et al., 2006). The tidal freshwater wetland ecosystem, which is located at the interface between terrestrial and aquatic ecosystems, has been identified as an important site for nitrate retention (Simpson et al., 1983; Bowden et al., 1986, 1987). Evaluation of ecosystem nitrate retention and its distribution within this ecosystem is required to develop controls on eutrophication in coastal zones (Boyer et al., 2006; Howarth and Marino, 2006; Seitzinger et al., 2006).

Tidal freshwater wetlands (TFWs) often contain selfformed channel networks that govern water and solute fluxes into these systems (Myrick and Leopold, 1963; Rinaldo et al., 2004). Tidal channel networks are similar to fluvial networks; geomorphic relationships among stream order, length, basin area, and inlet width have been defined for both fluvial (Horton, 1945; Strahler, 1952; Shreve, 1967) and tidal channel networks (Rinaldo et al., 1999b; Marani et al., 2003). Geomorphic scaling parameters have been used to evaluate nitrogen $(\mathrm{N})$ loads and processing in both terrestrial watersheds and tidal systems (e.g., Sferratore et al., 2005; Seitzinger et al., 2002). Previous research on N retention in TFW has identified marsh surfaces and near-surface environments as important sites for $\mathrm{N}$ processing (Bowden et al., 1986, 1987; Boynton et al., 2008). Normalized kinetic rate constants $\left(\mathrm{kg} \mathrm{N} \mathrm{yr}^{-1}\right)$ obtained from laboratory or field plot studies (e.g., Jenkins and Kemp, 1984; Caffrey et al., 1993; Joye and Paerl, 1994) have been used along with marsh surface area measurements and inundation times 


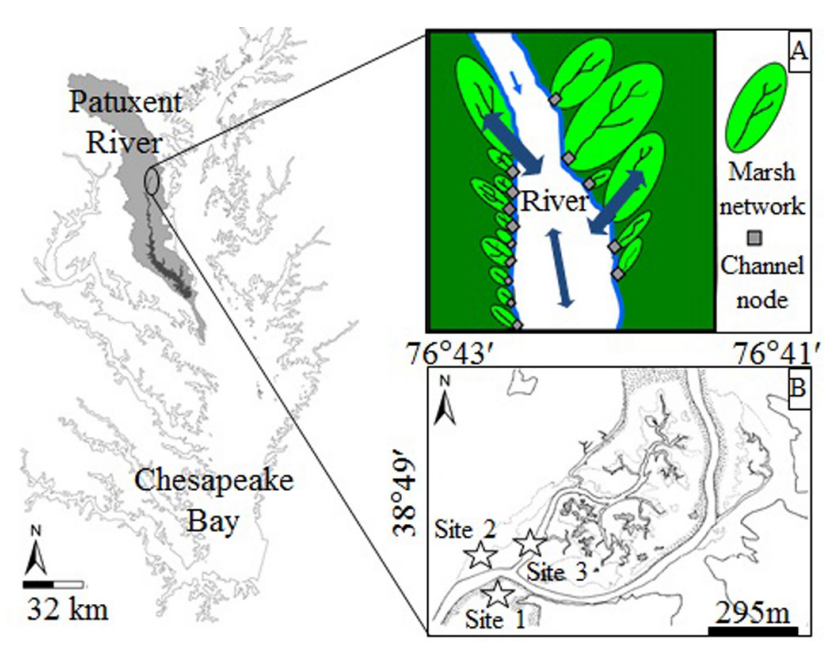

Fig. 1. Study area located in the tidal freshwater portion of the upper Patuxent River, Maryland. (A) Schematic diagram showing the organization of tidal marshes along the river. Tidal fluxes are controlled by inlet channel geomorphology (governing node). (B) Map of selected marshes for mass balance measurements. Marsh areas $\left(\mathrm{m}^{2}\right)$ are as follows: Site 1: 670.6, Site 2: 5705, Site 3: 536873.4 .

to upscale nitrogen retention for entire ecosystems (Boynton et al., 2008). Scaling nitrate retention to marsh surface area requires the following assumptions: marsh surface and near surface substrates are the dominant sites for nitrate retention; $\mathrm{N}$ processing rates are spatially homogeneous within marshes; and there is synchronous flooding of marsh surfaces of equal elevation. Several studies suggest that marsh materials are relatively homogeneous with little spatial variation in hydraulic properties (Harvey et al., 1987; Phemister, 2006) and nitrogen processing rates measured on marsh cores do not show systematic spatial variability (Cornwell et al., 1999; Merrill and Cornwell, 2000). Marsh-scale field studies of nitrate retention, however, indicate that in situ controls including inundation times may be complex and may involve parameters in addition to marsh surface area (e.g., Cornwell et al., 1999). Previous work on the Patuxent TFW ecosystem suggests that nitrate retention may be closely related to hydrologic flux in this system (Seldomridge and Prestegaard, 2011).

The purpose of this study is to evaluate geomorphic scaling parameters and to estimate total nitrate retention in TFW ecosystems. We obtained $\mathrm{N}$ retention data from field measurements of water fluxes and $\mathrm{N}$ species mass balance in marshes of varying sizes. These data were combined with geomorphic data for all marshes in the ecosystem to develop three equations (one for each geomorphic scaling parameter) to predict nitrate retention. Criteria used to evaluate geomorphic scaling parameters for nitrate retention are (a) accuracy of measurement of each geomorphic feature, (b) relationship between each geomorphic parameter and hydrologic flux, and (c) the ability to adjust the geomorphic parameters to varying tidal stages and hydrologic fluxes.

\section{Materials and methods}

\subsection{Study regions and approach}

The Patuxent River watershed $\left(2260 \mathrm{~km}^{2}\right)$ is located between Washington, D.C. and Baltimore, Maryland (Fig. 1). Land-uses in the basin include forest $(63.5 \%)$, agriculture $(20.3 \%)$, urban $(15.7 \%)$, and intertidal wetlands $(0.4 \%)$. Nitrate loads in the river have decreased in the past several decades largely due to reduction in point sources, but are still significantly higher than pristine watersheds (Fisher et al., 2006). The TFW ecosystem of the Patuxent River has been previously identified by Boynton et al. (2008); it extends approximately 25 river kilometers along the upper Patuxent River (from $39^{\circ} 0^{\prime} \mathrm{N} 76^{\circ} 41^{\prime} \mathrm{W}$ to $38^{\circ} 43^{\prime} \mathrm{N} 76^{\circ} 41^{\prime} \mathrm{W}$ ). This ecosystem is composed of hundreds of individual marshes with well-defined tidal creeks and marsh basin areas. The individual marshes are contained within protected parkland, Patuxent Wetland Park and Jug Bay Wetlands Sanctuary (Fig. 1). Plant species that border tidal channels include Nuphar advena/leteum, Peltandra virginica, Polygonum sagittatum, Pontederia cordata, and Zizania aquatica.

Each individual tidal freshwater marsh in this ecosystem connects to the tidal Patuxent River through a well-defined inlet channel (Fig. 1b). Natural levees border the marsh boundary, which prevents direct overbank flooding from the Patuxent River into the adjacent marsh for most tidal stages. Interior marsh areas are flooded by water that enters through the tidal inlet, and then moves up the tidal network, where it floods onto marsh surfaces (Seldomridge, 2009). Fringing tidal wetlands without channel networks also border the Patuxent River, but these higher elevation marshes are inundated only during the upper $10 \%$ of tidal or flood stages (high tide \pm high Patuxent River flow). Due to this geomorphic arrangement of marshes along the tidal Patuxent River, water and solute fluxes can be measured at the inlet of each individual marsh. Nitrate retention calculated from fluxes (e.g., Nitrate flux in - Nitrate flux out) measured at channel inlets represents the consequences of net nitrate retention processes within each individual marsh system.

\subsection{Geomorphic measurements and analysis}

Marsh surface area, channel length, inlet channel width, and channel order were measured from high-resolution air photos for every marsh and associated channel network in the tidal freshwater portion of the Patuxent River. Photo sources included United States Department of Agriculture (2006) and US Geological Survey (2002-2005; 2007-2010). Measurements were made from autumn and winter photographs to minimize measurement error due to vegetation 
Table 1. Geomorphic characteristics of marshes and mass balance measurements for autumn 2008.

\begin{tabular}{llll}
\hline & Site 1 & Site 2 & Site 3 \\
\hline Marsh surface area $\left(\mathrm{m}^{2}\right)$ & 670.6 & 5705 & 536873.4 \\
Total channel length $(\mathrm{m})$ & 21.6 & 124.6 & 1577.3 \\
Inlet channel width $(\mathrm{m})$ & 4.15 & 6.5 & 41.7 \\
Stream order & 2 & 3 & 7 \\
Inlet (maximum) depth $(\mathrm{m})$ & 0.59 & 0.79 & 2.0 \\
Inlet channel area $\left(\mathrm{m}^{2}\right)$ & 1.26 & 2.5 & 41.1 \\
Water volume $\left(\mathrm{m}^{3}\right)$ & $353 \pm 14$ & $1218 \pm 61$ & $16524 \pm 826$ \\
Nitrate retained $(\mathrm{mol})$ & $3.4 \pm 0.3$ & $10.6 \pm 0.2$ & $144.2 \pm 6$ \\
Nitrate retention rate per area $\left(\mathrm{mol} \mathrm{m}^{-2}\right)$ & 4439 & 1822 & 326 \\
Nitrate retention rate per volume $\left(\mu \mathrm{mol}^{-1}\right)$ & $8.5 \pm 0.6$ & $8.7 \pm 0.02$ & $8.7 \pm 0.1$ \\
Incoming nitrate $(\mathrm{mol})$ & 9 & 32 & 430 \\
\hline
\end{tabular}

cover. Channel order was determined following the Horton (1945) numbering scheme. Measurements of inlet channel widths and lengths from air photos were compared with field measurements of the same features to determine accuracy of measurement and the resolution of measurement (e.g., smallest measurable channel width). Marsh surface area for each tidal basin was determined from vegetation patterns and associated elevation changes, which were often subtle on images of the smallest tidal marshes (highest elevation). Thus, a subset of the smallest marshes (with areas less than $55 \mathrm{~m}^{2}$ ) could not accurately be determined. Operator error was determined from triplicate measurements of each geomorphic parameter. Operator error for channel width ranged from $1.72 \%$ for the smallest measured channel $(0.2 \mathrm{~m})$ to $1.29 \%$ for the largest measured channel $(93.4 \mathrm{~m})$; for channel length ranged from $1.5 \%$ for the smallest channel $(2.13 \mathrm{~m})$ to $0.03 \%$ for the largest channel $(3773.1 \mathrm{~m})$; and for marsh area ranged from $6.2 \%$ for the smallest measured areas $\left(225.6 \mathrm{~m}^{2}\right)$ to $0.15 \%$ for the largest measured areas $\left(675611.9 \mathrm{~m}^{2}\right)$.

To investigate ecosystem geomorphic characteristics, we evaluated cumulative size distributions of the geomorphic data. A cumulative distribution is determined by sorting the data from largest to smallest amount and plotting the cumulative number against size of the geomorphic characteristic on a $\log -\log$ plot. These distributions were evaluated to determine whether they exhibited power law behavior. The probability that an inlet width $(W)$ greater than or equal to $W_{\mathrm{i}}$ can be written as

$$
P\left(W \geq W_{\mathrm{i}}\right)
$$

Data exhibit an inverse power law if $P\left(W \geq W_{\mathrm{i}}\right)=\alpha W^{-\beta}$, where $\alpha$ and $\beta$ are empirically derived coefficient and exponent, respectively (Rinaldo et al., 1993; Scanlon et al., 2007). These distributions of geomorphic parameters were used to choose mass balance sampling locations, identify missing data, and assess the suitability of geomorphic parameters for modeling ecosystem nitrate retention.

\subsection{Site selection for inlet cross section and nitrate mass balance measurements}

Sites for field measurements of channel dimensions, water flux, and nitrogen mass balance measurements were chosen from the geomorphic probability distributions to represent a large range of tidal marsh sizes. Cross section measurements were made on 18 inlet channels, also chosen to represent the entire range of inlet channel sizes. Cross sections were measured at slack high tide of spring tidal stage conditions. Channel depth data were referenced to the high tide marsh platform elevations and tide gauge data.

Nitrate retention measured by mass balance procedures may be sensitive to tidal water volumes, incoming nitrate concentration, and height of marsh vegetation; therefore, measurements of individual marshes were conducted during high (spring) tides during the same or sequential tidal cycles (Seldomridge, 2009). Mass balance measurements were made at the inlets of three individual marshes that were in close proximity to one another with areas of 671,5705 , and $536873 \mathrm{~m}^{2}$, respectively (Fig. 1c). Additional geomorphic characteristics for each mass balance measurement site are given in Table 1. Although mass balance measurements of nitrate retention were made for varying seasons and tides (from 2008-2011), only the data for flooding tides of spring tidal conditions in early autumn (20 September 2008, 1 October 2008 and 14 September 2011, 16 September 2011) were used in the ecosystem evaluation in this paper. In this system, the exotic submerged aquatic vegetation Hydrilla verticillata influences vegetative flow resistance during spring and summer months (Jenner and Prestegaard, 2012), and thus affects water flux and nitrate retention. The autumn, spring tides represent a maximum water flux condition, for which we examined geomorphic influences on nitrate retention. 

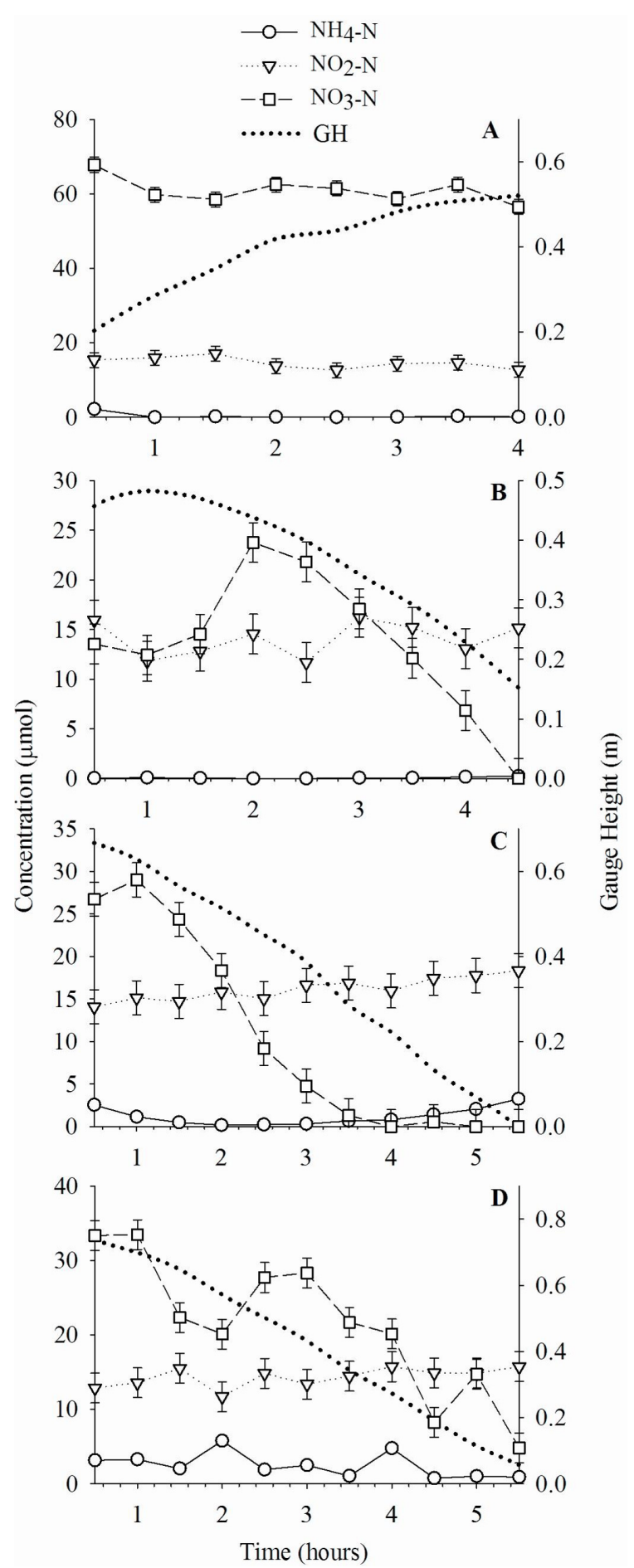

Fig. 2. Examples of water chemistry measurements. (A) Constant concentrations on incoming tides at Site 1 on 24 September 2008. (B) Nitrogen concentrations and tidal stage for the ebbing tidal cycle at Site 1 on 20 September 2008. The nitrate concentrations decrease with the dropping tidal stage. (C) Data for the ebbing tide at Site 2 on 1 October 2008. (D) Data for the ebbing tide at Site 3 on 1 October 2008.

\subsection{Measurement of hydrologic flux during spring (high) tides}

Hydrologic flux over a tidal cycle was determined by measuring tidal stage, associated channel cross-sectional area, and velocity at time steps during tidal cycles. Tidal stage was measured at each inlet. These local tidal stage measurements were referenced to continuously monitored gauges at Jug Bay Wetlands Sanctuary (Maryland Department of Natural Resources Eyes on the Bay). Bankfull (maximum) channel cross-sectional area was measured at slack high tides during spring tidal conditions. Velocity was measured at 10-12 intervals in the channel cross sections to determine discharge and average channel velocity $(Q / A)$. Due to the rapid change in velocity with tidal stage, a relationship between average and maximum velocity was developed for each channel (Chen and Chiu, 2002), and from field measurements of maximum velocity, this relationship was used to determine average velocity for each time step $(30 \mathrm{~min})$. Discharge calculations for each time step were integrated to determine total water volume $\left(V_{\mathrm{w}}\right)$ transported over the tidal cycle. A $5 \%$ error was propagated through all discharge calculations; this was determined by considering operator error in cross-sectional and velocity measurements (Sauer and Meyer, 1992), and error introduced by estimating average velocity from maximum velocity (Chen and Chiu, 2002).

\subsection{Calculation of tidal prism from tidal stage and geo- morphic data}

Field measurements of water volume $\left(V_{\mathrm{w}}\right)$ for spring tidal cycles were compared with values of spring tidal prism calculated for each marsh:

$V_{\mathrm{p}}=T_{\mathrm{r}} A_{\mathrm{ws}}$

where $V_{\mathrm{p}}$ is spring tidal prism $\left(\mathrm{m}^{3}\right), T_{\mathrm{r}}$ is spring tidal range (m), and $A_{\mathrm{ws}}$ is waterway surface area $\left(\mathrm{m}^{2}\right)$. Waterway surface area was determined from air photos. Local tidal range (and tidal period) for each individual marsh system is controlled by tidal stage and the elevation of the inlet channel relative to the marsh platform. For the smaller channels, inlet depth limits tidal stage and inundation time. Maximum channel depth for each inlet was determined from the inlet width $(W)$ to inlet area $\left(A_{\mathrm{c}}\right)$ relationship, and assuming triangular geometry that was indicated by field measurements. The relationship of spring tidal prism to geomorphic parameters (inlet cross-sectional area and marsh surface area) was also examined and compared to field measurements of spring tide water volume.

\subsection{Field mass balance measurements of nitrate reten- tion over spring tidal cycles}

Water sampling for $\mathrm{N}$ species $\left(\mathrm{NH}_{4}-\mathrm{N}, \mathrm{NO}_{2}-\mathrm{N}, \mathrm{NO}_{3}-\mathrm{N}\right)$ was conducted over spring tidal cycles. This maximum flooding 
condition was chosen to provide comparisons with laboratory conditions of marsh surface flooding, which produce maximum nitrate retention rates (Reddy et al., 1984). Water samples for the outgoing tidal cycle were measured in concert with gauge height and velocity measurements. Samples taken during flooding tides indicate that concentrations of $\mathrm{N}$ species remain nearly constant on the rising stage (Fig. 2a); therefore, sampling schemes were adopted that included only a portion of the flooding tide to obtain average incoming concentrations, along with the entire falling tide at each channel inlet sampling (Fig. 2b-d). Water samples were taken at $30 \mathrm{~min}$ intervals and filtered in the field with $45 \mu \mathrm{m}$ syringe filters. The samples were immediately frozen and analyzed within several weeks for dissolved inorganic nitrogen series $\left(\mathrm{NH}_{4}-\mathrm{N}, \mathrm{NO}_{2}-\mathrm{N}, \mathrm{NO}_{3}-\mathrm{N}\right)$ using standard photometric methods and ion chromatography (Solorzano, 1969; Keefe et al., 2004). Analytical error of $\pm 2 \mu \mathrm{mol}$, determined by the mechanical specifications of the equipment, was considered in all nitrate retention calculations.

Nitrate was the only form of nitrogen that shows significant variation over the tidal cycle, and is therefore the focus of this study (Fig. 2b-d). Nitrate retention was determined by subtracting the outgoing flux of nitrate from the average incoming nitrate flux for each tidal marsh for each time increment:

$\mathrm{NR}=\sum\left[Q_{t}\left(N_{\mathrm{i}(t)}-N_{\mathrm{o}(t)}\right)\right]$

where NR is nitrate retention (mol); $Q_{t}$ is discharge $\left(1 \mathrm{~s}^{-1}\right)$; $N_{\mathrm{i}(t)}$ is initial $\left[\mathrm{NO}_{3}-\mathrm{N}\right]$ of tidally introduced water $(\mu \mathrm{mol})$, and $N_{\mathrm{o}(t)}$ is $\left[\mathrm{NO}_{3}-\mathrm{N}\right]$ of outgoing tidal water at time $t$ in $\mu \mathrm{mol}$. One of the advantages of using mass balance calculations of nitrate retention is that it provides measurements of nitrate retention for individual marshes for a given tidal cycle, time of year, and initial nitrate concentration. No assumption is made of nitrogen retention processes within each individual marsh, although previous work suggests that marsh surfaces are primary sites for nitrate retention (Seldomridge, 2009).

Nitrate retention data were compared with both measured water volumes over a tidal cycle and marsh area to determine whether nitrate retention could be expressed as simple functions of either parameter. These results then guided the development of relationships between nitrate retention and geomorphic parameters.

\section{Results}

\subsection{Cumulative geomorphic distributions}

The data in the cumulative distributions can be described as inverse power law functions (Fig. 3). The power law for the cumulative number of marsh surface area is

$N=4712.3 A^{-0.54}, \quad n=142, \quad R^{2}=0.97$
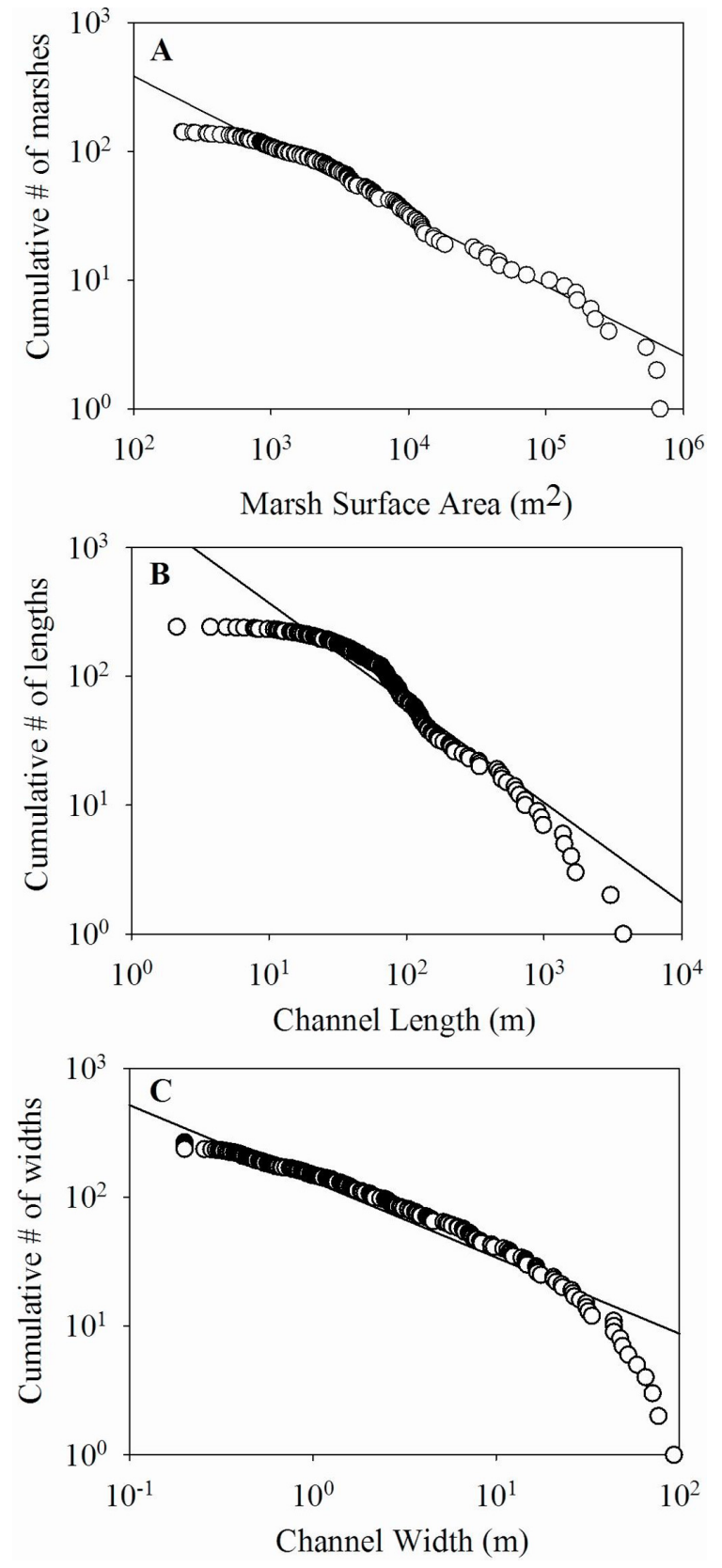

Fig. 3. Geomorphic data for the tidal freshwater portion of the Patuxent River. (A) Cumulative number of marsh areas less than or equal to indicated value $\left(N=4712.3 A^{-0.54}, n=142, R^{2}=0.96\right)$. (B) Cumulative number of channel lengths less than or equal to indicated size $\left(N=2224.1 L^{-0.78}, n=242, R^{2}=0.90\right)$. (C) Cumulative number of inlet channel widths less than or equal to indicated value $\left(N=133.23 W^{-0.59}, n=267, R^{2}=0.92\right)$. Standard error is less than size of data points.

where $N$ is the cumulative number of marshes with area $>A$. The power law for the cumulative number of channel lengths is

$N=2224.1 L^{-0.78}, \quad n=242, \quad R^{2}=0.90$ 

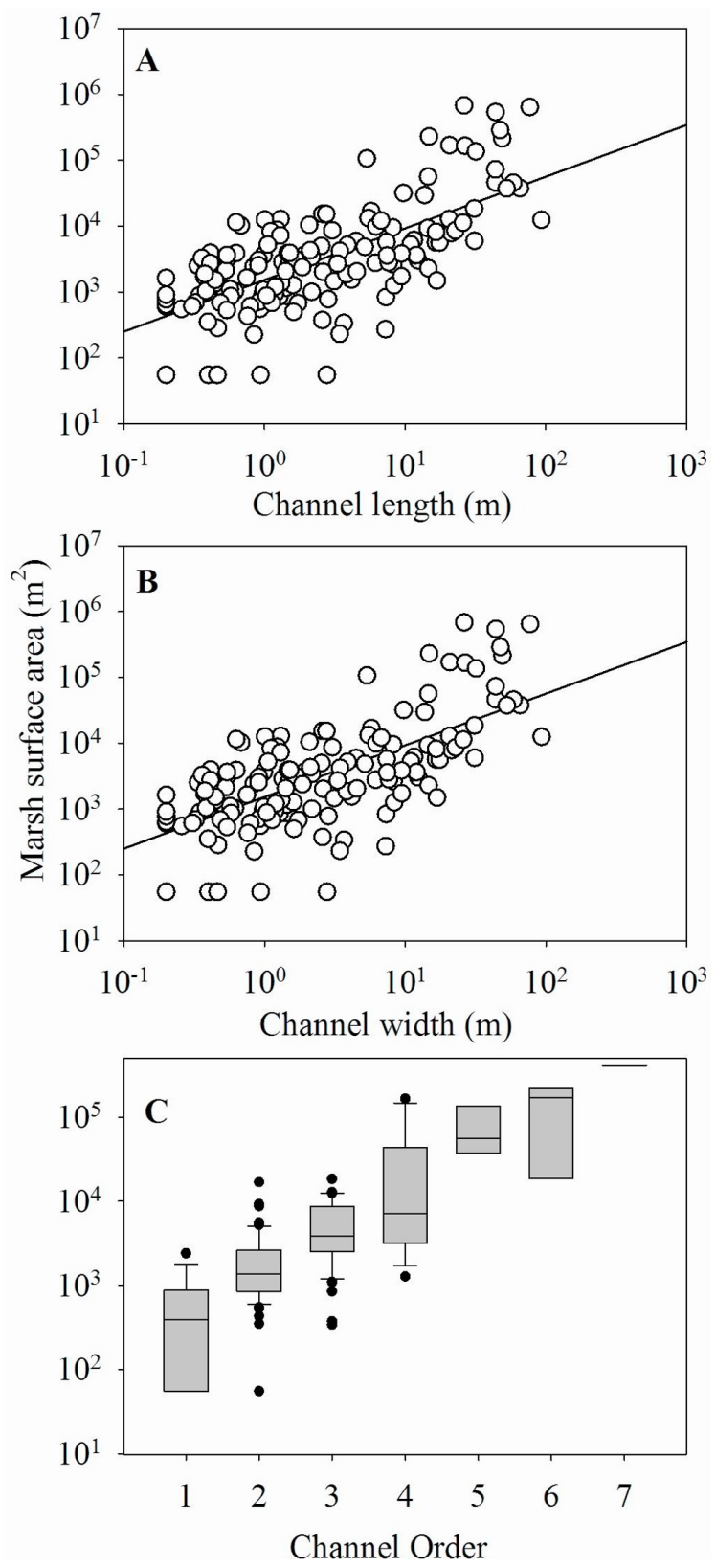

Fig. 4. Geomorphic relationships of channel order, inlet width, and total channel length to marsh surface area of tidal freshwater marshes along the Patuxent River estuary. (A) $L=1.3 A^{0.53}$ $\left(n=142, R^{2}=0.79\right)$. (B) $W=0.2 A^{0.65}\left(n=142, R^{2}=0.47\right)$. Standard error is less than the size of each data point. (C) Box plot of marsh surface areas for each stream order.

where $N$ is the cumulative number of channels with lengths $>L$. Finally, the power law for the cumulative number of inlet widths is

$N=133.2 W^{-0.59}, \quad n=267, \quad R^{2}=0.92$

where $N$ is the cumulative number of inlets with a width $>\mathrm{W}$. The smallest marsh inlet width measured from air photo data is $0.2 \pm 0.05 \mathrm{~m}$; this lower boundary was validated by field measurements.

\subsection{Relationships between geomorphic variables}

Inlet width measurements from air photos were the most accurate of the three geomorphic parameters (within $1 \%$ of measured values). Visibility of small inlets on photographs provided an almost complete inventory of inlet channels; therefore, the number of marsh inlets was used to define missing data for the other geomorphic parameters. Comparison of the number of inlet widths measured with channel length and marsh area measurements indicated that $47 \%$ of the total number of marsh area measurements (for the smallest marshes) and $9 \%$ of the channel length data are missing from the measured populations, although the width of the associated marsh inlet was identified. Relationships among the geomorphic variables were examined and are shown in Fig. 4; several of these relationships are given below:

$$
\begin{aligned}
L=1.3 A^{0.53}, & n=142, & R^{2}=0.79 \\
W=0.2 A^{0.65}, & n=142, & R^{2}=0.47
\end{aligned}
$$

where $L$ is the channel length, $W$ is the inlet width, and $A$ is the marsh surface area. Missing values for marsh surface area and channel length were estimated from their relationship to marsh width (e.g., Eq. 8).

Stream order was evaluated for each individual marsh channel network; maximum stream order for each marsh was determined, and the relationship between stream order and marsh area is shown in Fig. 4c. Stream order depends upon the choice of ordering system, the resolution of aerial photos and maps, and often fails to discern characteristics between network structures (Kirchner, 1993; Rinaldo and RodriguezIturbe, 1998); therefore, it was not used to model ecosystem nitrate retention in this study.

\subsection{Relationship of spring tidal volume to geomorphic parameters}

The relationships between spring tidal prism $\left(V_{\mathrm{p}}\right)$ and both marsh surface area $(A)$, and inlet channel cross-sectional area $\left(A_{\mathcal{C}}\right)$ are shown in Fig. 5. The relationship between bankfull inlet cross-sectional area and inlet width was developed from data on 18 channel inlets (Table 1; Fig. 5a):

$A_{\mathrm{c}}=0.20 W^{1.4}, \quad n=18, \quad R^{2}=0.88$

This relationship was used to estimate average and maximum inlet depth for each channel, which can be expressed as elevation relative to mean lower low water (Fig. 5b). The relationship of calculated spring tidal prism to inlet channel cross-sectional area (Fig. 5c) is

$V_{\mathrm{p}}=0.004 A_{\mathrm{c}}^{1.02}, \quad n=142, \quad R^{2}=0.65$

The field measurements of hydrologic volume over a tidal cycle are indicated in Fig. $5 \mathrm{c}$ as the three solid squares that plot near the central tendency of this relationship. 

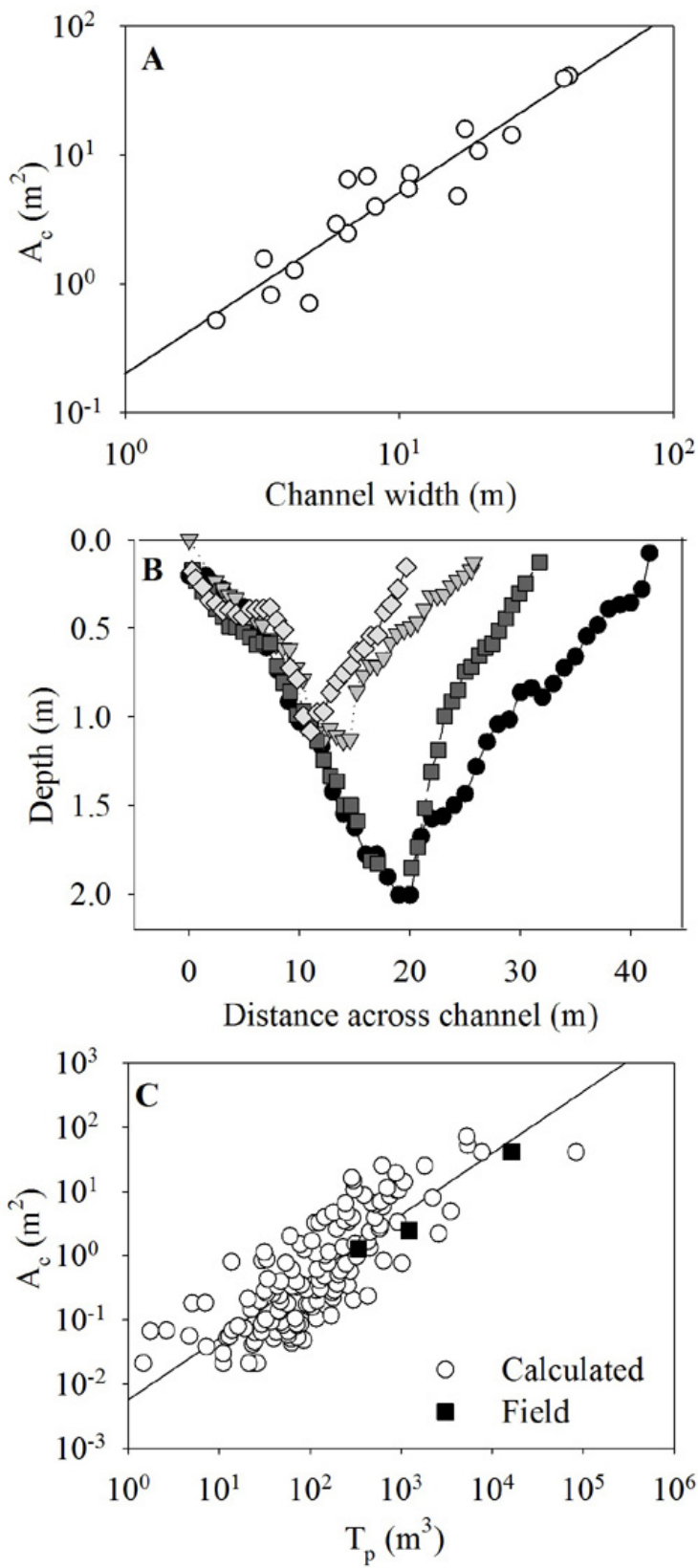

Fig. 5. Calculated spring tidal prism for tidal freshwater wetlands. (A) Relationship between inlet width and cross-sectional area. (B) Inlet channel cross-sectional areas plotted relative to the elevation of the marsh platform. Inlets with widths $>16 \mathrm{~m}$ experience the entire spring tidal range, whereas tidal range in the smaller inlets is constrained by inlet elevation, so that they experience a portion of high tidal stages. (C) Relationship between inlet cross-sectional area and tidal prism (Eq. 10). Squares indicate field measurement of spring tide water volumes for the three sampling sites.

The calculated tidal prism was expressed as a power function of each of the three geomorphic parameters (marsh area, channel length, and inlet channel width; Fig. 6). Field measurements of tidal water volumes (tidal prism) for the same
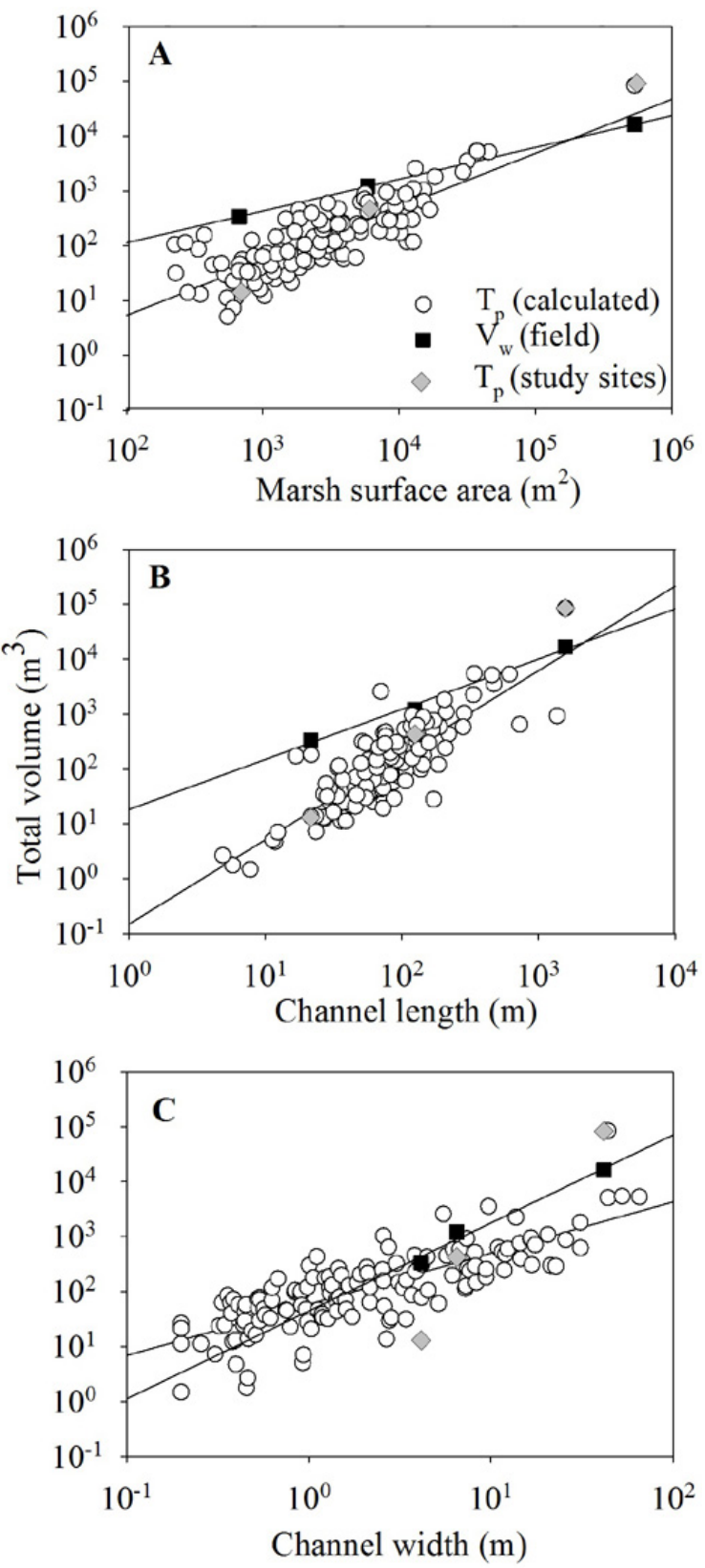

Fig. 6. Relationship of calculated tidal prism to (A) marsh surface area, (B) channel length, and (C) inlet channel width. Field measurements are shown as black squares; gray diamonds highlight predicted tidal prism for the corresponding study sites.

tidal stage are also indicated on these diagrams. These relationships indicate significant scatter between each geomorphic variable and tidal prism. In addition, there are systematic differences between the tidal prism estimates of water volume and the field measurements for all three geomorphic parameters (Fig. 6). These systematic differences suggest that the tidal prism method underestimates the amount of water carried into small tidal systems, but overestimates the amount carried into large tidal systems. 


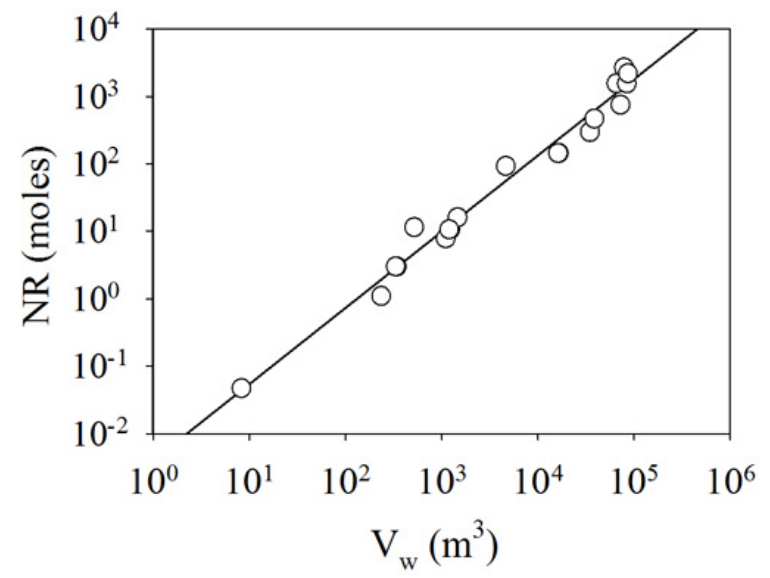

Fig. 7. Relationship between net nitrate retention over a tidal cycle and water volume. Data are reported for the three sampling sites for various tides in 2008, 2010, and 2011. Nitrate retention is a simple function of hydrologic flux that varies over 5 orders of magnitude. Seasonal multi-year data for spring (high tides) follow the relationship: NR $=0.0045 V^{1.1}\left(n=13, R^{2}=0.98\right)$.

\subsection{Mass balance results of nitrate retention}

The autumn data mass balance measurements of nitrate retention for each of the three marshes are shown in Table 1. These data indicate that the ratio of nitrate retention to water volume is constant for a given set of conditions. The data (Fig. 7) indicate a nearly linear relationship between water volume and nitrate retention for spring (high) tides, which aligns with the multi-year data for the entire growing season:

$\mathrm{NR}=0.0045 V_{\mathrm{w}}^{1.1}, \quad n=13, \quad R^{2}=0.98$

where NR is nitrate retention (mol) and $V_{\mathrm{w}}$ is the tidal volume water fluxed through the inlet channel mouth $\left(\mathrm{m}^{3}\right)$. When the exponent of 1.1 is rounded to 1 , the trend is linear and can be simplified to

$\mathrm{NR}=a V_{\text {in }}-b V_{\mathrm{out}}=c V_{\mathrm{w}}$

where NR is nitrate retention (mol), $a$ is the integrated average nitrate concentration ( $\mathrm{mol}$ ) on the incoming tide, $b$ is the integrated average nitrate concentration (mol) on the outgoing tide, $V_{\mathrm{w}}$ is the volume of water flux (l), and $c$ is the concentration of retained nitrate (mol). If $V_{\text {in }}=V_{\text {out }}$, which is the case for tides with minimal water storage or evapotranspirative losses, the equation is simplified to

$\mathrm{NR}=(a-b) V=c V$.

The relatively constant incoming nitrate concentrations were used to evaluate total nitrate flux into the tidal marshes (Table 1). These data indicate that approximately $30 \%$ of the total nitrate flux into the marshes was retained for the mea-
Table 2. List of equations describing geomorphic, hydrologic, and biogeochemical relationships.

\begin{tabular}{cc}
\hline \multicolumn{2}{c}{ Geomorphic-hydrologic } \\
\hline$V_{\mathrm{w}}=7.81 A^{0.58}$ & $n=3, R^{2}=1$ \\
$V_{\mathrm{W}}=18.15 L^{0.91}$ & $n=3, R^{2}=0.99$ \\
$V_{\mathrm{W}}=44.63 W^{1.6}$ & $n=3, R^{2}=0.98$ \\
\hline \multicolumn{2}{c}{ Geomorphic-biogeochemical } \\
\hline $\mathrm{NR}=0.0045 V_{\mathrm{W}}^{1.1}$ & $n=13, R^{2}=0.98$ \\
$\mathrm{NR}=0.038 A^{0.61}$ & $n=6, R^{2}=0.96$ \\
$\mathrm{NR}=0.09 L^{0.97}$ & $n=6, R^{2}=0.96$ \\
$\mathrm{NR}=0.25 W^{1.7}$ & $n=6, R^{2}=0.92$ \\
\hline
\end{tabular}

sured spring tides (Table 1). The constant ratio of NR/ $V$ (Table 1; Fig. 7) for varying values of incoming nitrate concentration suggests that retention is not limited by the range ( 23 to $57 \pm 2 \mu \mathrm{mol}$ ) of initial, incoming concentrations measured for this study.

\subsection{Comparison of ecosystem calculations of nitrate re- tention and evaluation of geomorphic parameters}

The relationship between water volume and nitrate retention relationship (Fig. 7) and the field-based relationship between water volume and each geomorphic parameter (Fig. 6) were combined to determine an equation between each geomorphic variable and nitrate retention (Table 2). These equations were then applied to the entire population of each geomorphic variable (Fig. 3) to estimate total nitrate retention for this TFW ecosystem (Fig. 8). Estimated total nitrate retention for the geomorphic parameters varied considerably; the estimate based on marsh area was only $44 \%$ of the value estimated from inlet width data. Nitrate retention for the reference spring tides (autumn 2008 and 2011) was $1738.9 \pm 44.6 \mathrm{~mol}$ $\mathrm{NO}_{3}-\mathrm{N}$ based on marsh area data, $2790.1 \pm 31.2$ mol NO $\mathrm{NO}_{3}-\mathrm{N}$ based on channel length data, and 3961.2 $\pm 135.8 \mathrm{~mol} \mathrm{NO}_{3}-$ $\mathrm{N}$ based on inlet width data. When the channel length and marsh surface area data were adjusted to account for missing measurements, the total nitrate retention was closer to the estimate based on inlet width (Fig. 8). The total nitrate retention based on adjusted marsh surface areas is $2254.9 \pm 44.6 \mathrm{~mol}$ $\mathrm{NO}_{3}-\mathrm{N}$, and for adjusted channel length is $2892.9 \pm 31.2 \mathrm{~mol}$ $\mathrm{NO}_{3}-\mathrm{N}$.

The distribution of total nitrate retention among the individual marshes as a function of channel width and marsh surface area is shown in Fig. 8b-c. As a function of channel width, the 8 widest channels ( $3 \%$ of total; ranging from $43.86 \mathrm{~m}$ wide to $93.39 \mathrm{~m}$ wide) are responsible for $50 \%$ of the NR. As a function of marsh surface area, the 11 biggest marshes ( $4 \%$ of total marsh area) are responsible for $50 \%$ of the NR; in sum these marshes cover $3227913 \mathrm{~m}^{2}$ or approximately $80 \%$ of the TFW ecosystem. Therefore, these largest 
marshes (top $4 \%$ ) represent a larger proportion of the total marsh area $(80 \%)$ than of total nitrate retention $(50 \%)$.

\section{Discussion}

\subsection{Geomorphic data and relationships}

In this study, the inlet width data were accurately measured from imagery data, relatively easy to field verify, and provided a nearly complete database that could be used to evaluate the quality of the other geomorphic databases. All of the geomorphic parameters exhibited power law behavior of cumulative data. Distributions were confined to 3 orders of magnitude for inlet width (Fig. 3), which suggest that minimum channel size may be affected by external controls, such as vegetation growth (Hickin, 1987; Rinaldo et al., 1999a; Montgomery, 1999). The upper limit of inlet size defines the maximum size of a tidal marsh that can be sustained in this system (Jenner, 2011), which is likely controlled by tidal stage and available space along the river width.

Although total length of the main channel network provides a measure of the conduit that conveys nutrient-rich waters into marsh interiors (Myrick and Leopold, 1963; Fagherazzi et al., 1999; Rinaldo et al., 1999b), this geomorphic parameter was also difficult to measure, particularly for large, complex marshes. In this study, the geomorphic system was composed of individual marshes arrayed along the length of the tidal Patuxent River, which is not directly analogous to the geomorphic organization of a large tidal system (e.g., Rinaldo et al., 2004). In this study, we found that total channel length was more closely related to tidal prism than marsh watershed area, which is the opposite of the result obtained by Marani et al. (2003) for a large, complex tidal marsh.

Previous studies have identified marsh surfaces as important sites for biogeochemical cycling (e.g., Bowden et al., 1986), and marsh area has previously been used as a scaling parameter to extend laboratory measurements of denitrification rates to field settings. Previous studies indicate that microtopography can greatly increase the overall area available for NR (Wolf et al., 2011); this study suggests that microtopography is only one of the difficulties presented in using marsh surface area as a scaling parameter. Non-synchronous flooding of surfaces of similar elevations as a function of travel time from the tidal inlet is an important issue in this system.

In this study, each freshwater tidal marsh was connected by a well-defined inlet channel to the main Patuxent River estuary. Thus, the inlet channel cross section area and tidal hydrodynamics control the amount of water, sediment, and solutes that move into the marshes (Fagherazzi et al., 1999). Using channel width as the geomorphic unit for scaling provided the highest estimate of ecosystem nitrate retention (Fig. 8), because every inlet channel, and thus every marsh system, was included in the ecosystem evaluation. This ge-

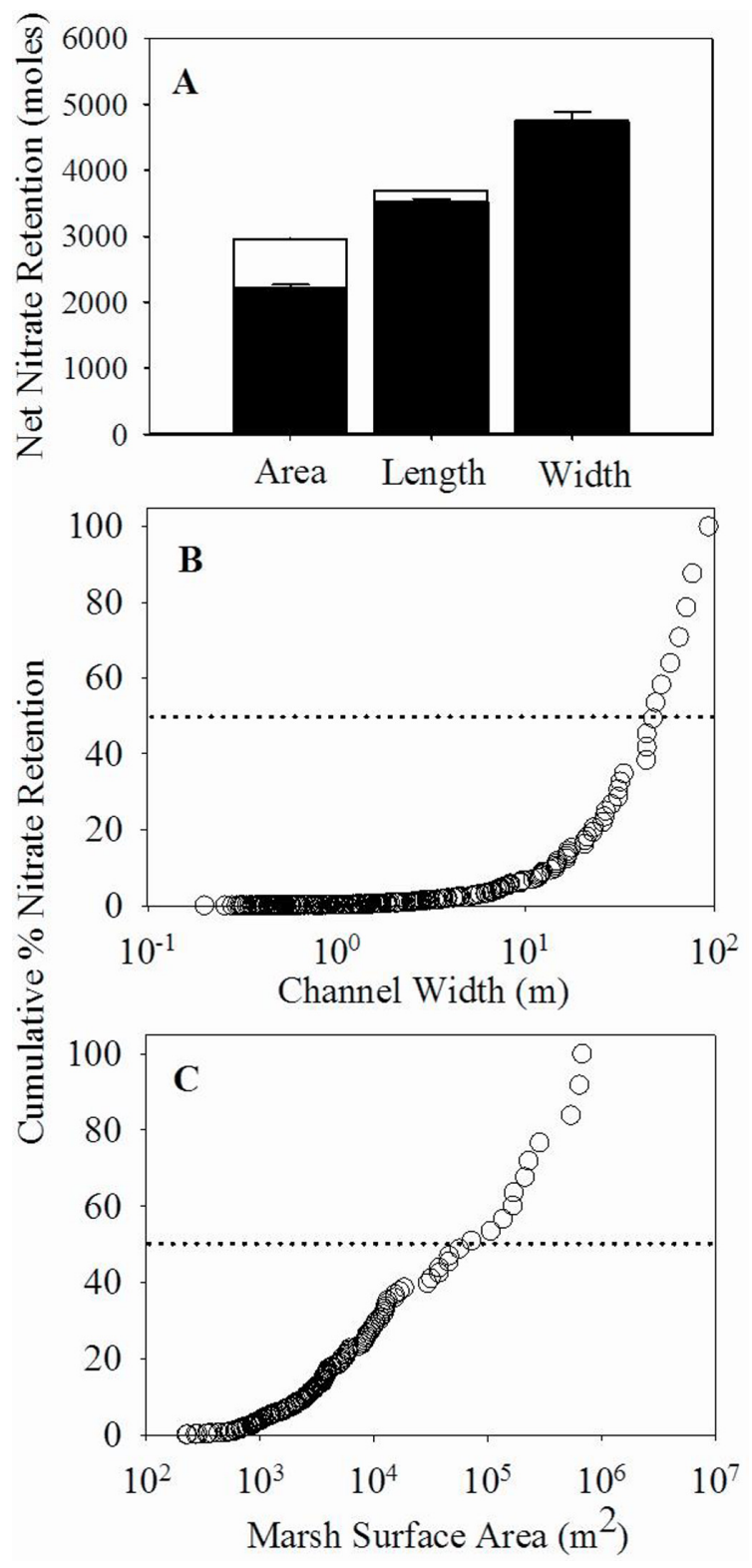

Fig. 8. Total ecosystem nitrate retention calculated from each of the three geomorphic variables. (A) Nitrate retention estimated from marsh surface area data is $1738.9 \pm 44.6 \mathrm{~mol} \mathrm{NO}_{3}-\mathrm{N}$, from channel length is $2790.1 \pm 31.2 \mathrm{~mol} \mathrm{NO} \mathrm{NO}_{3} \mathrm{~N}$, and from channel width is $3961.16 \pm 135.8 \mathrm{~mol} \mathrm{NO}_{3}-\mathrm{N}$. Stacked white bars indicate additional retention calculated by adding in the missing geomorphic data, which were predicted from geomorphic relationships to inlet width. (B) Spatial distribution of nitrate retention as a function of channel width; the 8 largest channels are responsible for $50 \%$ of total retention. (C) Spatial distribution of nitrate retention as a function of marsh surface area; the 11 largest marshes are responsible for $50 \%$ of total retention.

omorphic parameter is also easily adaptable to other tidal conditions through the relationships between channel width and hydraulic parameters (depth, velocity, area, discharge; 
Myrick and Leopold, 1963; Marani et al., 2003). Additional hydraulic measurements are necessary to constrain predictions of water fluxes with seasonally varying vegetation conditions, and will be explored in future work. Thus, for this tidal freshwater wetland ecosystem, with the simple arrangement of the marsh inlets along the sides of the estuary, inlet width provides the most complete and accurate data for estimating tidal water volumes and nitrate retention.

\subsection{Hydrologic controls on nitrate retention}

Tidal marshes are self-organized systems in which the marsh area coevolves with hydrologic flux to form the channel network system (Bak et al., 1988; Odum, 1988). This selforganization of tidal marsh networks generates systematic relationships between geomorphic characteristics and hydraulic characteristics (Fig. 4a, b). Mass balance studies indicated a nearly linear relationship between water volume and nitrate retention for spring (high) tides (Eq. 11), which suggests that nitrate retention is limited by hydrologic flux in this system (Seldomridge and Prestegaard, 2011). This relationship between hydrologic flux and nitrate retention relationships was similar for different seasons and tidal stages (Fig. 7). These data suggest that, although marsh surface area may be the dominant site for nitrate retention (Seitzinger, 1988; Cornwell et al., 1999), the ability of water to move through the system, even for the highest tides with minimum channel flow resistance, is the greatest control on nitrogen processing. Marsh areas that are available for processing have limited activity due to limitations in water reaching these sites. Nitrate retention includes a variety of processes such as denitrification, biotic assimilation, burial, and/or recycling. These processes are seasonally variable and may be controlled by factors such as temperature, the availability of organic matter, amount of oxygen, nitrogen availability, and composition of the microbial community (e.g., Seitzinger, 1988, 1994; Cornwell et al., 1999; Wallenstein et al., 2006). Although these controls may be seasonally important, results from this study suggest that nitrate retention in these freshwater tidal wetlands is strongly correlated to water volumes. Evaluation of additional hydrodynamic data is needed to use geomorphic data (inlet width, inlet area) to predict tidal volumes, and thus nitrate retention for other tidal stages and seasons.

\subsection{Spatial distribution of nitrate retention}

Although the small-sized marsh systems are the most common (Fig. 3), the spatial distributions of nitrate retention indicate that a small number of the biggest marshes are responsible for the majority of retention (Fig. 8b, c). The largest $4 \%$ of the marshes by area represented $80 \%$ of the total area and retained $50 \%$ of the total nitrate. Although numerous, the small marshes contributed small proportions to the total nitrate retention due to the short inundation times of these high elevation surfaces. Previous studies suggest that small marshes with high surface area to volume ratios are the important sites for nitrate retention (e.g., Simpson et al., 1983; Groffman, 1994; Boynton et al., 2008). Although we also observed the largest surface area to volume ratios for the small systems (Table 1), it is the volume of water that limits the nitrate retention in this system, not the area to volume ratio.

\section{Conclusions}

The appropriate geomorphic unit for scaling an ecosystem function must be chosen based on both underlying controls (e.g., water volume), and also on data availability and accuracy of measurement. For this study, field measurements of in situ nitrogen processing rates on multiple scales were necessary to determine the appropriate scaling parameters to estimate ecosystem nitrate retention. We suggest that mass balance measurements might be appropriate as fundamental steps to determine scaling parameters in other systems. Although the results of this study appear to be related to the geomorphic organization of TFW along the main estuary, and thus might not be directly applicable to other tidal freshwater wetlands, the integrated mass balance and geomorphic approach should be applicable to other ecosystems. In addition, any other ecosystem function that is linked to hydrologic flux, such as sediment transport and deposition, allochthonous organic carbon retention, and perhaps sulfate retention, can be analyzed using this approach. This study presents spatially-distributed estimates of nitrate retention for one representative high tidal stage. Additional work is necessary to determine hydrodynamic and other data required to evaluate nitrate retention for temporally varying conditions (e.g., seasonal and tidal variations in hydrodynamic and nitrogen processing).

Acknowledgements. Jeffrey Cornwell and Mike Owens, Horn Point Laboratory, University of Maryland Center for Environmental Sciences provided lab assistance and advice that greatly improved this project. This research was conducted under an award from the Estuarine Reserves Division, Office of Ocean and Coastal Resource Management, National Ocean Service, National Oceanic and Atmospheric Administration.

Edited by: T. J. Battin

\section{References}

Bak, P., Tang, C., and Wiesenfeld, K.: Self-organized criticality, Am. Phys. Soc., 38, 364-374, 1988.

Bowden, W. B.: Nitrification, nitrate reduction, and nitrogen immobilization in a tidal freshwater marsh sediment, Ecology, 67, 88-99, 1986.

Bowden, W. B.: The biogeochemistry of nitrogen in freshwater wetlands, Biogeochemistry, 4, 314-348, 1987. 
Boyer, E. W., Alexander, R. B., Parton, W. J., Li, C., ButterbachBahl, K., Donner, S. D., Skaggs, R. W., and Del Grosso, S. J.: Modeling denitrification in terrestrial and aquatic ecosystems at regional scales, Ecol. Appl., 16, 2123-2142, 2006.

Boynton, W. R., Hagy, J. D., Cornwell, J. C., Kemp, W. M., Greene, S. M., Owens, M. S., Baker, J. E., and Larsen, R. K.: Nutrient budgets and management actions in the Patuxent River Estuary, Maryland, Estuar. Coast, 31, doi:10.1007/s12237-0089052-9, 2008.

Caffrey, J. M., Sloth, N. P., Kaspar, H. F., and Blackburn, T. H.: Effect of organic loading on nitrification and denitrification in a marine sediment microcosm, FEMS Microbiol. Ecol., 12, 159167, 1993.

Chen, Y.-C. and Chiu, C.-L.: An efficient method of discharge measurement in tidal streams, J. Hydrol., 265, 212-224, 2002.

Cornwell, J. C., Kemp, W. M., and Kana, T. M.: Denitrification in coastal ecosystems: methods, environmental controls, and ecosystem level controls, a review, Aquat. Ecol., 33, 41-54, 1999.

Fagherazzi, S., Bortoluzzi, A., Dietrich, W. E., Adami, A., Lanzoni, S., Marani, M., and Rinaldo, A.: Tidal networks: 1. Automatic network extraction and preliminary scaling features from digital terrain maps, Water Resour. Res., 35, 3891-3904, 1999.

Fisher, T. R., Hagy, J. D., Boynton, W. R., and Williams, M. R.: Cultural eutrophication in the Choptank and Patuxent estuaries of Chesapeake Bay, Limnol. Oceanogr., 51, 435-447, 2006.

Groffman, P. M.: Denitrification in freshwater wetlands, Curr. Top. Wetland Biogeochem., 1, 15-35, 1994.

Harvey, J. W., Germann, P. F., and Odum, W. B.: Geomorphological control of subsurface hydrology in the creekbank zone of tidal marshes, Estuar. Coast. Shelf S., 25, 677-691, 1987.

Hickin, E. J.: Vegetation and river channel dynamics, Can. Geogr., 28, 111-126, 1987.

Horton, R. E.: Erosional development of streams and their drainage basins hydrophysical approach to quantitative morphology, Geol. Soc. Am. Bull., 56, 275-370, 1945.

Howarth, R. W. and Marino, R.: Nitrogen as the limiting nutrient for eutrophication in coastal marine ecosystems: evolving views over three decades, Limnol. Oceanogr., 51, 364-376, 2006.

Jenkins, M. C. and Kemp, W. M.: The coupling of nitrification and denitrification in two estuarine sediments, Limnol. Oceanogr., 29, 609-619, 1984.

Jenner, B. A.: Geomorphic and hydrologic controls on tidal prism and inlet cross sectional area for Chesapeake Bay lagoons, MS Thesis, University of Maryland, College Park, 2011.

Jenner, B. A. and Prestegaard, K. L.: Effects of submerged aquatic vegetation on flow resistance and hydraulic geometry in a freshwater tidal marsh, Geomorphology, in review, 2012.

Joye, S. B. and Paerl, H. W.: Nitrogen cycling in microbial mats: rates and patterns of denitrification and nitrogen fixation, Mar. Biol., 119, 285-295, 1994.

Keefe, C. W., Blodniker, K. L., Boynton, W. R., Clark, C. A., Frank, J. M., Kaumeyer, N. L., Weir, M. W., Wood, K. V., and Zimmermann, C. F.: Nutrient analytical services laboratory standard operating procedures, Technical Report Number SS-80-04CBL, Chesapeake Biological Laboratory, 2004.

Kirchner, J. W.: Statistical inevitability of Horton's laws and the apparent randomness of stream channel networks, Geology, 21, 591-594, 1993.
Marani, M., Belluco, E., D’Alpaos, A., Defina, A., Lanzoni, S., and Rinadlo, A.: On the drainage density of tidal networks, Water Resour. Res., 39, doi:10.1029/2001WR001051, 2003.

Merrill, J. Z. and Cornwell, J. C.: The role of oligohaline marshes in estuarine nutrient cycling, in: Concepts and Controversies in Tidal Marsh Ecology, edited by: Weinstein, M. P. and Kreeger, D. A., Kluwer Academic Publ., Dordrecht, Netherlands, 425-441, 2000.

Montgomery, D. R.: Process domains and the river continuum, J. Am. Water Resour. As., 35, 397-410, 1999.

Myrick, R. M. and Leopold, L. B.: Hydraulic geometry of a small tidal estuary, physiographic and hydraulic studies of rivers, US Geological Survey Professional Paper 422-B, 18 pp., 1963.

Odum, H. T.: Self-organization, transformity, and information, Science, 242, 1132-1139, 1988.

Phemister, K.: Characterization of the spatial differences in hydrological functioning in a tidal marsh, Patuxent River, MD: A framework for understanding nutrient dynamics, MS Thesis, University of Maryland, College Park, 2006.

Reddy, K. R., Patrick, W. H., and Broadbent, F. E.: Nitrogen transformations and loss in floodedsoils and sediments, CRC Crit. Rev. Environ. Contr., 13, 273-309, doi:10.1080/10643388409381709, 1984.

Rinaldo, A. and Rodriguez-Iturbe, I.: Channel networks, Annu. Rev. Earth Planet. Sci., 26, 289-327, 1998.

Rinaldo, A., Rodriguez-Iturbe, I., Rigon, R., Ijjasz-Vazquez, E., and Bras, R. L.: Self-organized fractal river networks, Phys. Rev. Lett., 70, 1222-1226, 1993.

Rinaldo, A., Fagherazzi, S., Lanzoni, S., and Marani, M.: Tidal networks 2. Watershed delineation and comparative network morphology, Water Resour. Res., 35, 3905-3917, 1999a.

Rinaldo A., Fagherazzi, S., Lanzoni, S., Marani, M., and Dietrich, W.: Tidal networks 1 . Watershed delineation and comparative network morphology, Water Resour. Res., 35, 3905-3917, 1999b.

Rinaldo, A., Belluco, E., D’Alpaos, A., Feola, A., Lanzoni, S., and Marani, M.: Tidal networks: Form and function, in: Ecogeomorphology of Tidal Marshes, edited by: Fagherazzi, S., Blum, L., and Marani, M., American Geophysical Union, Coastal and Estuarine Monograph Series, Washington D.C., 1-18, 2004.

Sauer, V. B. and Meyer, R. W.: Determination of error in individual discharge measurements, US Geological Survey Professional Paper 92-144, 21 pp., 1992.

Scanlon, T. M., Caylor, K. K., Levin, S. A., and RodriguezIturbe, I.: Positive feedbacks promote power-law clustering of Kalahari vegetation, Nature, 449, 209-212, doi:10.1038/nature06060, 2007.

Seitzinger, S. P.: Denitrification in freshwater and coastal marine systems: ecological and geochemical significance, Limnol. Oceanogr., 33, 702-724, 1988.

Seitzinger, S. P.: Linkages between organic matter mineralization and denitrification in eight riparian wetlands, Biogeochemistry, 25, 19-39, 1994.

Seitzinger, S. P., Styles, R. V., Boyer, E. W., Alexander, R. B., Billen, G., Howarth, R. W., Mayer, B., and van Breemen, M.: Nitrogen retention in rivers: Model development and application to watersheds in the Northeastern USA, Biogeochemistry, 57/58, 199-237, 2002. 
Seitzinger, S. P., Harrison, J. A., Böhlke, J. K., Bouwman, A. F., Lowrance, R., Peterson, B., Tobias, C., and van Drecht, G.: Denitrification across landscapes and waterscapes: a synthesis, Ecol. Appl., 16, 2064-2090, 2006.

Seldomridge, E.: Importance of channel networks on nitrate retention in freshwater tidal wetlands, Patuxent River, MS Thesis, University of Maryland, College Park, 2009.

Seldomridge, E. and Prestegaard, K.: Is denitrification kineticallylimited or transport-limited in tidal marshes?, Appl. Geochem., 26, S256-S258, doi:10.1016/j.apgeochem.2011.03.117, 2011.

Sferratore, A., Billen, G., Garnier, J., and Thery, S.: Modeling nutrient $(\mathrm{N}, \mathrm{P}, \mathrm{Si})$ budget in the Seine watershed: Application of the Riverstraher model musing data from local to global scale resolution, Global Biogeochemical Cy., 19, GB4S07, doi:10.1029/2005GB002496, 2005.

Shreve, R. L.: Infinite topologically random channel networks, J. Geol., 75, 178-186, 1967.
Simpson, R. L., Good, R. E., Leck, M. A., and Whigham, D. F.: The ecology of freshwater tidal wetlands, BioScience, 33, 255-259, 1983.

Solorzano, L.: Determination of ammonia in natural waters by the phenolhypochlorite method, Limnol. Oceanogr., 14, 799-801, 1969.

Strahler, A. N.: Hypsometric (area-altitude) analysis of erosional topology, Geol. Soc. Am. Bull., 63, 1117-1142, 1952.

Wallenstien, M. D., Myrold, D. D., Firestone, M., and Voytek, M.: Environmental controls on denitrifying communities and denitrification rates: insights from molecular methods, Ecol. Appl., 16, 2143-2152, 2006.

Wolf, K. L., Ahn, C., and Noe, G. B.: Microtopography enhances nitrogen cycling and removal in created mitigation wetlands, Ecol. Eng., 37, 1398-1406, 2011. 